\title{
USING ECONOMIC VALUE ADDED IN EX-ANTE PROFITABILITY CALCULATION OF BANK'S MEDIUM-SIZED CLIENTS
}

\section{Štěpánka Křečková*}

\begin{abstract}
This article deals with the calculation of bank's medium-sized enterprises clients' ex-ante profitability and the possibility to use Economic Value Added (EVA) tools in such calculation instead of, currently in bank sector, widely used measure of Risk Adjusted Return on Capital (RAROC). Using a sample of medium-sized enterprises clients to whom a credit exposure was approved in one of the banks operating on the bank's market within a country belonging to the European Union, the expected profitability of these clients was compared by using firstly RAROC and then compared the results to the profitability calculation using EVA tool on the same set of data. Although both measures (RAROC and EVA) are based on the same initial variables, the results of profitability measure show different outcomes in terms of clients' profitability level and thus their contribution to the total clients' portfolio profitability. Using EVA tool instead of RAROC measurement thus could help bank's relationship managers and branch managers focus on those clients creating larger value added than others.
\end{abstract}

Keywords: Economic Value Added (EVA), Risk Adjusted Return on Capital (RAROC) JEL Classification: G29

\section{Introduction}

Since 1989 when EVA tool was introduced by the consulting company Stern Stewart \& Co., many specialised publications have been dealing with this tool, its detail description of methodology and application, mainly in production and services (or more precisely non-financial) companies (Damodaran, 1999; Frykman and Tolleryd, 2010; Grant, 1997; Griffith, 2004; Stern, Rolss and Shiely, 2001; Stern and Chew, 2003; Stern, 2004; Stern and Willett, 2014; Stewart, 1995, 1999, 2013). EVA tool has, nevertheless, wide utilization within banks and other financial companies, thus there is not much publications and authors drawing attention to it. One of the areas where EVA could be used is in profitability calculations of bank's corporate clients, or more precisely in profitability of at least medium-sized enterprises that are clients of the bank. Banks usually divide their client's portfolio into three segments, i.e. retail, small and medium-sized enterprises and corporate clients. The retail segment is created by individuals and non-entrepreneurs, the small and medium-sized enterprises segment is created by small entrepreneurs and business entities, the corporate segment is then created by large corporate entities. Each segment has their own specific needs for bank products regardless of if we are

* Štěpánka Křečková, Faculty of Finance and Accounting, University of Economics in Prague,

Prague, Czech Republic (xkres07@vse.cz).

This paper was prepared within the research projects of Faculty of Finance and Accounting of University of Economics, Prague, realized with the institutional support of University of Economics, No. IP100040. 
talking about deposits or loans. Furthermore, in this paper a bank's client will refer to credited clients, only because credit loans are the products that really earn money for the banks and their shareholders. Retail clients aim usually for credit cards, consumer loans and mortgages, their individual credit exposures are small comparing to the whole credit exposure of all bank's segments and if one of these individuals defaults, resulting loss from this default is not crucial for the bank. When banks evaluate these retail clients and set the loan prices, they use scoring tools and the pricing of products for individuals are set by a bank's uniform price list. The small and medium-sized enterprises segment is composed of small entrepreneurs asking usually for business credit cards and loans for financing of small investments into their business. These clients are also evaluated by a uniform bank's scoring tool and the prices are set according to a given price list. In opposition medium-sized and large corporate enterprises have different needs for bank products varying from need of financing their working capital, financing of large investments helping the business to grow to pre-finance subsidies (in case of medium-sized enterprises) or financing of acquisitions of daughter companies in case of corporate clients. This means, prior to providing credit exposure these medium-sized and corporate clients are evaluated by both the banks' rating tools and also individually. The bank's credit department professionals "manually" evaluate client's financial and business risk and the whole process of providing credit exposure from evaluating to setting prices and loan conditions is basically individualized for each client. This individual approach to these corporate and medium-sized clients means also a special approach for monitoring their profitability and in case of price setting also calculation of ex-ante profitabitity. As will be further explained banks are currently using mainly ratio measurements for client's profitability calculation, which provides only a limitied information. The aim of this paper is therefore to focus on usage of EVA as ex-ante profitability measure of medium-sized enterprises clients used in banks as an alternative to RAROC measure. ${ }^{1}$

The paper is organized as follows: the next section reviews the literature so far published on this subject. Section 3 deals with variables used in RAROC calculation and subsequently in EVA in more details. Section 4 describes in more detail the suggested methodology. Section 5 introduces the dataset and applies the methodology introduced in Section 4 using this dataset to test whether the usage of EVA tool provides different results about the bank's clients compared to the RAROC measurement, even though both measures are basically based on the same variables. Section 6 concludes the paper and states final remarks.

\section{Literature Review}

As mentioned above for the evaluations of company's clients the banks use rating tools combining both, financial and non-financial criteria of a company. The resulting rating than determine the so called PD rating (Probability of Default rating) of a client showing the probability of default of this client. The ratings vary from low to high risk clients.

Apart from client profitability, both RAROC and EVA measures can be also used for calculation of transaction (product) profitability or even particular bank segments profitability. This article is, nevertheless, used on client's profitability calculation only. 
Depending on the PD rating (and therefore the risk of default) to which the client is placed the pricing of the products is then set. The banks' products and services are mostly the same or very similar (when we talk about the biggest players on the market) and the price is often the main criterion according to which the clients chose among the banks' offers. On the other hand, when setting the prices the banks have to respect the risk of particular clients (expressed by PD rating) and of the credit exposure provided to them. Obviously the higher the risk of a client the higher margin should be provided to balance the riskiness of the client. But how the bank could recognize the lowest margin that could still be provided to an individual corporate (medium-sized enterprises) client in order to make profit out of this client? In order to generate a profit and create value for the shareholders banks have to undergo certain risks and consider them in performance measurement, which should be risk adjusted and calculated when the credit exposure is provided to the clients, therefore ex-ante. When forecasting the ex-ante profitability of the clients upon providing loan products they must respect the client's riskiness and the bank's risk capital that should be allocated to this client in order to cover the unexpected losses, operating risks and market risks (Crouhy, Turnbull and Wakeman, 1999) from the credit exposures. The banks use various measures mostly in a form of a ratio (comparing profit from clients to the risk capital allocated to them). To create a profit, the ratio should then be greater than the return required by bank's shareholders. This return is in banks often referred as hurdle rate. If we abstract from traditional performance measures, such as ROA or ROE, which take into consideration only return and costs without considering also the risks that have to be taken in order to receive the profit, than one of the widely used ratio for ex-ante bank client's profitability calculation is Risk Adjusted Return on Capital (RAROC), which in its simplest form is represented by the following Equation:

$$
R A R O C=\frac{G R-O C-E L}{\text { Risk_Capital }}>h r
$$

Where $G R$ represents the gross expected revenues, $O C$ stands for operating costs, $E L$ are expected losses and $h r$ is required hurdle rate. The clients whose RAROC is greater than required hurdle rate are than supposed to create value for the shareholders.

Currently used concept of RAROC has been known since the late 1970s when it was introduced by Dan Borge, the managing director and partner at American Banker's Trust Company. RAROC measure is specially used by banks and other financial institutions for capital allocation because of their special financial profile and capital structure resulting from their business, which distinguishes them from other industrial and service providing firms (i.e. non-financial companies). In contrast to non-financial business, banks are dealing with clients who may be as well their liability holders and consequently the costs of leverage are highly important for the banks comparing to non-financial companies (Merton and Perold, 1993). Without positive credit rating the banks would not be able to continue in their business and liberal leverage could even cause the default. To prevent this, bank sector is, nevertheless, subject to severe regulation. Since then it has been used not only for capital budgeting and allocation, but also for performance measurement (Zaik, Walter, Kelling 
and James, 1996; Froot and Stein, 1998a and 1998b; Crouhy, Turnbull and Wakeman, 1999; Culp, 2000; Crouhy, Galai and Mark, 2001; Schroeck, 2002; Stoughton and Zechner, 2004; Saita, 2007). There are also a number of ratios based on variously modified RAROC, such as RARORAC (Risk Adjusted Return on Risk Adjusted Capital), which is basically RAROC minus the RAROC target $k_{e}-r_{f}$, where $k_{e}$ represents the target return for equity capital and $r_{f}$ is the risk-free rate (Saita 2007).

$$
R A R O R A C=\frac{G R-O C-E L}{\text { Risk_Capital }}-\left(k_{e}-r_{f}\right)=R A R O C-\left(k_{e}-r_{f}\right)
$$

The most crucial component of RAROC is a cost of equity capital and its determination. Some authors (Zaik, Walter, Kelling and James, 1996; Crouhy, Galai, Mark, 2001) recommend using a single hurdle rate for evaluation of clients' performance as a cost of capital, which should be consistent with the long-term target return on capital of the bank. Zaik, Walter, Kelling and James (1996) assume that a stand-alone business unit (or a client in our case) is adding value to shareholder if it's RAROC is higher than the cost of the bank's equity (i.e. the minimum rate or return required by shareholders). Other authors emphasizing a usage of a single hurdle rate for different lines of business may lead to a decision adversely affecting shareholder value. According to Crouhy, Turnbull and Wakeman (1999) usage of a single hurdle rate of all business units may lead to preferring more risky investments. Consequently they recommend the usage of the so-called adjusted RAROC that should be greater than the market portfolio expected return as the following Equation shows:

$$
\text { Adjusted_RAROC }=\frac{R A R O C-r_{f}}{\beta_{E}}>E\left(R_{M}\right)-r_{f}
$$

Where $\beta_{E}$ stands for bank's stock equity beta, which depends on the beta of the risky asset and leverage and $E\left(R_{M}\right)-r_{f}$ is market portfolio expected excess return. Instead of usage adjusted RAROC, Milne and Onorato (2007) suggest adjusting the numerator of Equation 1 in order to use a single hurdle rate. The adjustment is shown by the following formula:

$$
R A R O C=\frac{G R-E L-M C o R-O C}{\text { Risk_Capital }}>0
$$

$M C o R$ in the formula stands for the market cost of risk that can also be interpreted as the cost of hedging or insuring risk on the market. The hurdle rate should than be zero and the authors recommend this concept for slow growing retail banks with a high margin.

In some literature it is also possible to reveal some other alternatives of RAROC. Nevertheless, they are based on the same principals, such as ROEC (Return on Economic Capital), which is mentioned by Uyemura and Van Deventer (1993) representing the earnings of a business unit divided by the capital allocated to these earnings.

All these above mentioned client's profitability measures have one thing in common, they are all ratios, which means that by using them the bank managers can detect, which businesses (clients) are creating value added to the bank's shareholders and which are not. Such tools are used in banks especially for large corporate clients, to which (and their 
pricing) as already mentioned above, the banks have an individual approach. The segment of medium-sized enterprises clients can in large banks count for thousands of clients. Which means that using such tools for profitability measurements of clients recruiting from medium-sized enterprises could lead to accepting all loans (clients) generating value added, yet without knowing the absolute level of value added to the whole portfolio. Consequently, a bank can finally administrate a large portfolio of medium-sized enterprise clients albeit generating value added, which, however, might be even higher when changing the structure of clients' portfolio. Shareholders are finally interested in the amount of value added created, regardless of how many clients/loans it was generated by. A certain solution to this may be through the usage of an alternative ex-ante profitability measure calculating an absolute value added by a client. Uyemura and Van Deventer (1993) mention Shareholder Value Added (SVA), which is defined as "Dollar earnings in excess of the hurdle return on "economic" capital", which is basically the very same concept as Economic Value Added (EVA). EVA as a profitability measure in banks and other financial institutions was introduced by Uyemura, Kantor and Pettit (1996). Since then many authors have been dealing with this tool, and if EVA is mentioned as a profitability measure in financial institutions (usually as an alternative to widely used RAROC) other authors and publications are actually referring to this article (like Schroeck, 2002 or Stoughton and Zechner, 2004). Kraus (2013) further compares various tools used for value-based management in life and non-life insurance business and finally recommends usage of tools based on discounted cash flow such as Market Value Added or Market Consistent Embedded Value.

All these above mentioned tools (apart from SVA and EVA) for profitability calcu-lation have one thing in common: they are all ratios. Therefore, they measure only the relative profitability, which only says whether the client is acceptable for the bank with respect to the rate of return required by shareholders. Nevertheless, the two clients with the same level of relative profitability can actually create different absolute amounts of value added, which managers using only RAROC measure (or its modifications) cannot immediately see. As will be further explained knowing the absolute amount of value added created by each client can, nevertheless, be valuable information for the bank managers who are administrating huge portfolio of clients.

\section{Description of Variables}

In order to understand the usage of EVA tool in valuation of ex-ante profitability of bank's clients instead of currently widely spread RAROC, it is initially necessary to understand well the variables used to calculate RAROC measure.

RAROC is a relative indicator that measures the net profit realized by a bank from its client (or transaction, or a whole segment) upon providing loan products to this client in relation to the risk capital required for covering of unexpected losses from the credit exposure provided to this client (as expressed by Equation 1). Some authors also call this risk capital as "capital at risk" (Saita, 2007). When we tax the gross profit in numerator Equation 1 we get the net profit from credit exposure provided to a client to risk capital for covering of unexpected losses, as expressed by Equation 5: 


$$
R A R O C=\frac{(G R-O C-E L) \times(1-t)}{\text { Risk_Capital }}
$$

Where $t$ stands for tax rate. Other particular variables will be now briefly introduced.

Gross Return includes all revenues from realized credit deals with a client, mainly interest margin and further income from loan fees. On the client's level, it can also include income from ancillary business, which means income resulting even from non-credit operations with the client, such as deposit or financial market operations.

Operational costs connected to the provided credit exposure on the client level are not unambiguously assignable in banks as they are in the case of production companies. There are no material costs or costs related to a credit exposure provided to bank clients. Costs of internal business units cooperating on the provided credit exposure are therefore allocated to individual clients, usually according to some allocation drivers and ABC model (Activity Based Costing model).

Expected loss is a loss realized from provided credit deals, which can be with some probability, expected. In banks the expected losses are forecasted with special bank models based primarily on historical data and the forecasted amount of expected losses. This is then treated as cost influencing the profit from realized credit deals. In practice the expected loss should be close to the amount of created credit provisions. The expected losses should be covered by the credit provisions related to the credit exposure in default (i.e. the debtors related to this credit exposure are not able to repay it). Furthermore, the unexpected losses should be covered by the capital, or more precisely the risk capital as stated in Equation 1.

Risk capital is the capital determined to cover the unexpected losses. With the modifications of BASEL II and BASEL III and regulatory requirements in banks the risk capital converges more and more to the regulatory capital.

Hurdle rate is, as already mentioned above, a minimum required rate of return each client with a provided credit exposure should achieve in order for the economic costs to be covered and for the client to create an economic profit (i.e. a value added). The determination of an eligible hurdle rate is a difficult task. It should be established on the level of cost of equity (in order to cover the necessary costs) plus some additional value (in order to create value). So far the most used method of determination of the cost of equity in the banking sector is one-factor model CAPM (Capital Assets Pricing Model). Nevertheless, some authors (Crouhy, Turnbull, Wakeman, 1999) emphasize that CAPM does not take into consideration the costs related to default and therefore the hurdle rate which is determined according to the CAPM does not reflect all the costs of economic capital. This topic is, nevertheless, far more complex and behind the aim of this article.

The issue of determination and forecasting all the above variables (especially of expected loss, risk capital and hurdle rate) is much wider. Nevertheless, dealing with this issue in more details is not the main aim of this article, therefore it will not be further analysed here. For studying this topic in more detail, please consult the respective literature. 


\section{Methodology}

Calculation of RAROC itself, nevertheless, does not express the feasibility and profitability of the credited clients. In order to assess such profitability, it is necessary to compare the calculated RAROC with an appropriate value expressing a minimum required rate of capital return. In banks, such a value is often referred to as a hurdle rate and its minimal level should be the level of costs of capital, i.e. the capital determined for covering the unexpected losses ${ }^{2}$ in order to cover at least all the economic costs. In order for a bank to receive a profit from a business (a credited client), the hurdle rate should be at such a level so that the loan deal generates a profit after covering all the economic costs. In other words, if the required rate of return is $h r$ then the credited client (the loan deal) should be accepted under condition given by Equation 6:

$$
R A R O C>h r
$$

Comparing computed RAROC with the hurdle rate required by a bank, nevertheless, does not say anything about the absolute amount of value added created by the realized credited deal (the client). The RAROC measure only shows that a credited client creates a value added for a bank, in case the RAROC calculated on this client exceeds the required hurdle rate. If the RAROC measure is under the required level of hurdle rate, this client is not creating value added for the bank, as the economic costs spent on this client (and the credit deals realized with such a client) do not exceed the realized income from this client. From this perspective EVA tool can be a more suitable profitability measure of credited bank clients than RAROC, as EVA shows the absolute amount of value added realized from the particular client. Through the absolute amount of added value created by the client, its contribution can then become more apparent to the total value of the whole portfolio. Ex-ante profitability calculation via EVA tool can be utilized upon the decision making of the pricing policy, or more precisely of the margin level provided to particular client upon providing a credit exposure. Especially nowadays when the bank interest rates are on minimum level and the banking market is becoming more and more competitive. As for clients often cooperating with more financial institutions, the loan price offered by the banks in most cases is the most important measure when deciding which bank they want to sign the loan contract with. If the relationship managers used EVA for exante profitability calculation, they could immediately see the impact on the margin level on the amount of value created. This information would help them when they negotiate with bank clients on conditions of provided credit exposure including the product price. If the EVA measurement were used by banks upon planning (e.g. planned EVA on segment level or on branch level) and the bonuses for managers were linked to a certain planned level of achieved EVA, the managers could immediately see the impact on credit exposure price provided to a client. Therefore the coordination of the achievement of the total plans (branches or segments) could be easier. On the contrary, when using RAROC measure

2 In Equation 1 this capital is referred as risk capital. 
for ex-ante client's profitability calculation, only the percentage profitability of clients is computed, which tells only (upon comparing to required hurdle rate) if the client is profitable or not, regardless of the absolute value added it creates. This approach can lead to accepting deals with high percentage RAROC creating low value added in absolute value. Using EVA measure for ex-ante client's profitability calculation instead, would in contrary mean, the branch managers could better diversify and administrate their client's portfolio. They could focus on clients with higher value added, instead of administrating huge portfolios, creating additional costs (especially personnel costs as wider client's portfolio needs to be administrated by more relationship managers).

The next issue is the application of EVA measure used especially in non-financial institutions on data of bank's clients. Literature focussed on the EVA tool works with a number of slightly modified formulas, out of which the following one is the most often presented (e.g. Stewart, 1999):

$$
E V A=N O P A T-c \times \text { capital }
$$

Where NOPAT is the Net Operating Profit After Tax, i.e. the profit from the core business of a company, $c^{*}$ capital is a charge for the use of capital necessary for operating a company's core business. NOPAT used in EVA calculation is moreover modified by all random or onoff revenues and expenses. The profit realized by a bank directly from a credited client also contains only revenues and expenses linked to that client and transactions realized with them. Therefore NOPAT in Equation 7 can be considered equal to the net profit computed in numerator of Equation 5. Capital in the Equation 7 is the capital determined to achieve related NOPAT and therefore it can be considered equal to the risk capital allocated to covering the unexpected losses in Equation 5 as shown in Equation 8:

$$
E V A=N O P A T-c \times \text { capital }=(G R-O C-E L) \times(1-t)-R C \times h r
$$

Alternatively:

$$
E V A=(G R-O C-E L) \times(1-t)-R C \times h r
$$

To summarize the above, the theoretical basis of usage of EVA tool for ex-ante bank client's profitability calculation instead of RAROC measure are as follows:

- $\quad$ RAROC $\rightarrow$ is a ratio that only computes if a particular client is worth being credited in relation to the hurdle rate required by a bank, but not what is the participation of the client to the total value of the portfolio. Consequently the clients with high level of RAROC can actually produce lower added value than clients with lower RAROC level, but higher absolute EVA. Usage of RAROC measure for ex-ante client's profitability calculation can mean the individual relationship managers and branches can therefore be wrongly focussed on clients, in fact generating lower value for banks.

- $\quad$ EVA $\rightarrow$ on the contrary measures ex-ante profitability of bank's clients in absolute amounts and therefore can express the contribution of each client to the economic profit of the whole portfolio. 


\section{Empirical Analysis}

The theoretical grounds introduced in Section 3 were applied on the real portfolio of bank clients, in order to demonstrate the differences between RAROC methodology and EVA approach. The empirical analysis was performed in one of the banks operating on the bank's market within a country belonging to the European Union. As the number of small and medium-sized enterprises clients in this particular bank's portfolio is almost 130 thousand (including both, small entrepreneurs and medium-sized business companies). In order of obtaining better data and manipulation, the clients for the research reasons were selected according to the following key: only medium-sized enterprises clients requesting new credit exposure, which was approved on the level of local steering committee in the first 6 months in 2014 were included (which amounted to 138 clients). The reasons for such data selection are strictly pragmatic as the bank clients' data are generally very sensitive and confidential and acquiring such figures is always strictly limited. Nevertheless, these restrictions have no impact on the research results. Out of these 138 clients there were ultimately excluded specific clients like municipalities, housing co-operative and flat owners associations, hospitals or non-profit organisations because of their specificity (for instance special models used for computing their PD rating). Additionally, clients requesting more than 3 credit lines were excluded from the reason of data-intensity. Finally 102 medium-sized enterprises clients were included into the research. The clients are arranged in chronological order, i.e. according to the date when the RAROC was calculated and the credit request arrived to the approval process. Table 1 below shows the surveyed clients' data. The total credit exposure provided to these clients was EUR 33.79 million, the lowest provided credit exposure on client's level was EUR 36 thousand (client No. 31). The highest amount of credit exposure on client's level was EUR 1.44 million (client No. 24). The particular, variables were calculated according to the following rules:

Total Credit Exposure is a sum of the total provided credit exposure to the client including all credit lines.

$P D$ rating (Probability of Default) reflects the credit-worthiness of each client determined by financial and non-financial characteristics and is modelled by the bank's internal models. In the surveyed bank, it ranks the clients into eight ${ }^{3}$ categories $1-8$, where PD 1 is assigned to the clients with low probability of default (i.e. clients with lowest risk) and PD 8 is, on the contrary, assigned to the clients with high probability of default (i.e. clients with highest risk). The PD rating is also shown in percentage, expressing the average probability of the client's default.

Interest Income was calculated according to the following Equation: Interest Income = Interest Margin x Drawn Portion of the Credit Exposure + Commitment Fee x Undrawn Portion of the Credit Exposure, where Commitment Fee is basically a margin provided for undrawn part of the credit exposure.

3 There are 13 categories together in the surveyed bank, nevertheless, in categories 9-13 there are classified clients already managed by Department of Bad Debts, who are not part of the surveyed client's sample. 
Non-Credit Income is a sum of the income coming from ancillary business, i.e. other operations and business done with the clients not related to the credit exposure. It includes income from client's bank deposits + income from realized payment transactions + income from foreign exchange transactions.

Total Fee Income is a sum of all fee income related to the provided credit exposure.

Gross Return as described in Part 2 is then the sum of the three above income items, i.e. Interest Income + Non-Credit Income + Total Fee Income

Operational Costs should reflect all the costs for the operation of individual bank's branches, banking systems, campaign etc. cooperating on the provided credit exposure for the clients. These costs should be then allocated to individual clients according to some allocation drivers (e.g. Saita, 2007) as described in Part 3. This approach is usually applied for the calculation of ex-post RAROC, where the variables are based on actual figures. In case of ex-ante calculation of RAROC, there the variables can be only estimated. One possible approach for the operational costs estimation (used also in the surveyed bank) is via Cost/Income ratio. It serves as an approximation of the real operational costs per client. The Cost to Income ratio a key financial measure monitored by banks, which in terms of RAROC calculation serves as an approximation of the real operational costs per client. In 2014 (on which data the survey was conducted) the surveyed bank's Cost/Income ratio set for ex-ante RAROC calculation was 46.4. And the estimated operational costs are calculated as Gross Return x Cost/Income ratio. ${ }^{4}$

Expected Loss is a loss due to credit and is calculated according to the following Equation: Expected Loss = Probability of Default x Loss Given Default x Exposure at Default, where Loss Given Default is a percentage of exposure, which is expected to be lost in the case that default occurs. It is modelled by the bank's internal models. Exposure of Default is a volume of exposure expected at the moment of default. It is also modelled by the bank's internal models.

Net Profit in Table 1 expresses the numerator in Equation 5, as it is calculated as (Gross Return - Operational Cost - Expected Loss) - Tax.

Risk Capital is calculated as Capitalization Target x Risk Weighted Assets, where Risk Weighted Assets are calculated according the BASEL II requirements, Capitalisation Target is set in the surveyed bank at $8 \%$.

Hurdle rate as explained in Part 3 should be established on the level of cost of equity (in order to cover the necessary costs) plus some additional value (in order to create value). The Cost of Equity at the surveyed bank are set to 8\%. It means that each RAROC calculated on the client's level has to reach at least $8 \%$. This is the minimum level of RAROC in order for all the costs to be covered, but no profit would be generated, which means EVA would be 0 . Therefore, when calculating EVA the hurdle rate was chosen on the level of Cost of Equity i.e. $8 \%$.

$4 \quad$ As clients with higher exposures tend to have higher Gross Return, this approach to Operational Costs calculation will lead to higher Operational Costs. Which is not necessary true and is one of the limitation factor of this approach to the estimated Operational Costs calculation. 
Table 1a | RAROC and EVA of Surveyed Bank's Clients

\begin{tabular}{|c|c|c|c|c|c|c|c|c|c|c|c|c|c|c|c|}
\hline Client & $\begin{array}{c}\text { Total } \\
\text { Credit } \\
\text { Exposure } \\
\text { in } € \text { ths }\end{array}$ & $\begin{array}{l}\text { PD } \\
\text { rating }\end{array}$ & PD \% & $\begin{array}{l}\text { Interest } \\
\text { Income } \\
\text { in } € \text { ths }\end{array}$ & $\begin{array}{l}\text { Non- } \\
\text { credit } \\
\text { Income } \\
\text { in } € \text { ths }\end{array}$ & $\begin{array}{l}\text { Total } \\
\text { Fee } \\
\text { Income } \\
\text { in } € \text { ths }\end{array}$ & $\begin{array}{l}\text { Opera- } \\
\text { tional } \\
\text { Costs } \\
\text { in } € \text { ths }\end{array}$ & $\begin{array}{c}\text { Ex- } \\
\text { pected } \\
\text { Loss }\end{array}$ & $\begin{array}{c}\text { Tax } \\
\text { in } € \text { ths }\end{array}$ & $\begin{array}{c}\text { Net } \\
\text { Profit } \\
\text { in } € \text { ths }\end{array}$ & $\begin{array}{c}\text { Risk } \\
\text { Capital } \\
\text { in } € \text { ths }\end{array}$ & $\begin{array}{c}\text { RAROC } \\
\text { in } \%\end{array}$ & $\begin{array}{c}\text { EVA in } \\
€ \text { ths }\end{array}$ & $\begin{array}{l}\text { Clients' } \\
\text { order- } \\
\text { RAROC }\end{array}$ & $\begin{array}{c}\text { Clients' } \\
\text { order - } \\
\text { EVA }\end{array}$ \\
\hline 1 & 324.62 & 2 & 0.14 & 3.97 & 4.80 & 0.43 & 4.27 & 0.146 & 0.91 & 3.87 & 5.85 & 66.22 & 3.40 & 31 & 33 \\
\hline 2 & 180.34 & 5 & 1.13 & 3.61 & 5.77 & 0.65 & 4.65 & 1.050 & 0.82 & 3.50 & 13.49 & 25.96 & 2.42 & 78 & 49 \\
\hline 3 & 793.51 & 5 & 1.13 & 14.28 & 0.54 & 0.16 & 6.95 & 0.009 & 1.52 & 6.50 & 0.18 & 3613.85 & 6.48 & 7 & 1 \\
\hline 4 & 468.89 & 7 & 4.53 & 9.38 & 6.85 & 1.02 & 8.01 & 2.699 & 1.24 & 5.30 & 15.94 & 33.28 & 4.03 & 58 & 21 \\
\hline 5 & 265.72 & 4 & 0.57 & 6.70 & 2.45 & 0.49 & 4.48 & 0.192 & 0.95 & 4.03 & 5.95 & 67.83 & 3.56 & 30 & 31 \\
\hline 6 & 445.45 & 5 & 1.13 & 5.09 & 0.36 & 0.56 & 2.78 & 0.558 & 0.51 & 2.15 & 8.68 & 24.82 & 1.46 & 92 & 81 \\
\hline 7 & 252.48 & 6 & 2.26 & 5.33 & 0.76 & 0.76 & 3.17 & 0.702 & 0.56 & 2.40 & 5.85 & 41.08 & 1.93 & 43 & 66 \\
\hline 8 & 516.14 & 5 & 1.13 & 7.74 & 1.98 & 1.05 & 5.00 & 1.488 & 0.81 & 3.47 & 19.12 & 18.16 & 1.94 & 102 & 65 \\
\hline 9 & 216.41 & 7 & 4.53 & 2.38 & 5.48 & 0.32 & 3.80 & 1.397 & 0.57 & 2.42 & 7.39 & 32.78 & 1.83 & 61 & 73 \\
\hline 10 & 168.98 & 6 & 2.26 & 5.91 & 0.43 & 0.31 & 3.09 & 0.485 & 0.59 & 2.50 & 6.09 & 40.99 & 2.01 & 44 & 63 \\
\hline 11 & 504.96 & 4 & 0.57 & 9.09 & 8.30 & 0.85 & 8.46 & 1.000 & 1.67 & 7.11 & 27.64 & 25.72 & 4.90 & 81 & 10 \\
\hline 12 & 396.75 & 3 & 0.28 & 5.36 & 0.36 & 0.26 & 2.77 & 0.141 & 0.58 & 2.48 & 7.37 & 33.67 & 1.89 & 57 & 72 \\
\hline 13 & 180.34 & 6 & 2.26 & 3.75 & 0.54 & 0.28 & 2.12 & 0.487 & 0.37 & 1.59 & 4.06 & 39.27 & 1.27 & 46 & 88 \\
\hline 14 & 541.03 & 6 & 2.26 & 10.82 & 5.05 & 0.65 & 7.66 & 2.013 & 1.30 & 5.54 & 16.76 & 33.06 & 4.20 & 60 & 20 \\
\hline 15 & 196.93 & 4 & 0.57 & 5.12 & 4.15 & 0.27 & 4.43 & 0.033 & 0.97 & 4.11 & 1.14 & 361.81 & 4.02 & 9 & 22 \\
\hline 16 & 288.55 & 2 & 0.14 & 2.89 & 1.44 & 0.18 & 2.09 & 0.036 & 0.45 & 1.93 & 2.73 & 70.64 & 1.71 & 29 & 76 \\
\hline 17 & 108.21 & 6 & 2.26 & 1.39 & 1.44 & 0.38 & 1.49 & 0.002 & 0.33 & 1.39 & 0.01 & 9847.86 & 1.39 & 3 & 84 \\
\hline 18 & 57.71 & 6 & 2.26 & 3.85 & 0.11 & 0.12 & 1.89 & 0.477 & 0.32 & 1.38 & 5.60 & 24.73 & 0.94 & 93 & 98 \\
\hline 19 & 90.17 & 5 & 1.13 & 1.06 & 2.52 & 0.29 & 1.80 & 0.397 & 0.32 & 1.36 & 5.10 & 26.67 & 0.95 & 74 & 97 \\
\hline 20 & 360.69 & 5 & 1.13 & 5.41 & 14.03 & 0.40 & 9.20 & 2.294 & 1.58 & 6.75 & 29.47 & 22.92 & 4.40 & 96 & 15 \\
\hline 21 & 360.69 & 4 & 0.57 & 8.66 & 1.44 & 0.25 & 4.80 & 0.370 & 0.98 & 4.19 & 12.62 & 33.23 & 3.18 & 59 & 36 \\
\hline 22 & 360.69 & 4 & 0.57 & 5.59 & 7.94 & 0.68 & 6.59 & 0.810 & 1.29 & 5.51 & 21.02 & 26.22 & 3.83 & 76 & 26 \\
\hline 23 & 72.14 & 6 & 2.26 & 1.26 & 1.80 & 0.12 & 1.48 & 0.337 & 0.26 & 1.11 & 4.23 & 26.22 & 0.77 & 77 & 100 \\
\hline 24 & 1442.74 & 3 & 0.28 & 12.98 & 0.90 & 0.02 & 6.45 & 0.407 & 1.34 & 5.71 & 21.24 & 26.86 & 4.01 & 72 & 23 \\
\hline 25 & 108.21 & 5 & 1.13 & 1.48 & 3.61 & 0.47 & 2.58 & 0.495 & 0.47 & 2.01 & 6.36 & 31.65 & 1.50 & 63 & 80 \\
\hline 26 & 180.34 & 4 & 0.57 & 1.35 & 3.72 & 0.20 & 2.44 & 0.382 & 0.46 & 1.98 & 7.04 & 28.09 & 1.41 & 68 & 83 \\
\hline 27 & 288.91 & 6 & 2.26 & 4.87 & 6.53 & 0.38 & 5.46 & 0.005 & 1.20 & 5.11 & 0.04 & 12469.76 & 5.11 & 1 & 9 \\
\hline 28 & 162.31 & 5 & 1.13 & 2.11 & 1.05 & 0.24 & 1.58 & 0.364 & 0.28 & 1.18 & 4.68 & 25.21 & 0.81 & 86 & 99 \\
\hline 29 & 180.34 & 7 & 4.53 & 4.40 & 7.94 & 0.40 & 5.91 & 0.307 & 1.24 & 5.28 & 1.62 & 324.96 & 5.15 & 10 & 8 \\
\hline 30 & 360.69 & 6 & 2.26 & 6.85 & 2.16 & 1.12 & 4.70 & 1.140 & 0.82 & 3.48 & 9.50 & 36.60 & 2.72 & 51 & 45 \\
\hline 31 & 36.07 & 3 & 0.28 & 0.97 & 3.75 & 0.29 & 2.33 & 0.039 & 0.50 & 2.14 & 0.98 & 219.86 & 2.07 & 14 & 60 \\
\hline 32 & 1082.06 & 2 & 0.14 & 11.36 & 4.33 & 0.22 & 7.38 & 0.424 & 1.54 & 6.56 & 32.26 & 20.34 & 3.98 & 101 & 24 \\
\hline 33 & 201.55 & 3 & 0.28 & 7.17 & 7.79 & 0.56 & 7.20 & 0.216 & 1.54 & 6.57 & 11.01 & 59.63 & 5.69 & 33 & 6 \\
\hline 34 & 205.09 & 5 & 1.13 & 5.54 & 0.00 & 0.35 & 2.73 & 0.249 & 0.55 & 2.35 & 5.31 & 44.35 & 1.93 & 40 & 67 \\
\hline 35 & 180.34 & 6 & 2.26 & 2.84 & 1.98 & 0.54 & 2.49 & 0.183 & 0.51 & 2.18 & 1.52 & 143.54 & 2.06 & 16 & 61 \\
\hline 36 & 363.68 & 4 & 0.57 & 4.91 & 0.61 & 0.62 & 2.85 & 0.142 & 0.60 & 2.55 & 2.62 & 97.62 & 2.35 & 21 & 51 \\
\hline 37 & 180.34 & 3 & 0.28 & 1.48 & 3.25 & 0.65 & 2.49 & 0.185 & 0.51 & 2.18 & 4.62 & 47.27 & 1.81 & 36 & 75 \\
\hline 38 & 865.64 & 5 & 1.13 & 8.51 & 3.25 & 0.79 & 5.82 & 0.635 & 1.16 & 4.93 & 8.17 & 60.37 & 4.28 & 32 & 17 \\
\hline 39 & 541.03 & 6 & 2.26 & 7.07 & 8.66 & 2.11 & 8.28 & 2.662 & 1.31 & 5.59 & 22.18 & 25.19 & 3.81 & 87 & 27 \\
\hline 40 & 216.41 & 5 & 1.13 & 0.43 & 7.65 & 0.32 & 3.90 & 0.291 & 0.80 & 3.41 & 3.74 & 91.19 & 3.11 & 22 & 39 \\
\hline 41 & 360.69 & 5 & 1.13 & 2.13 & 2.16 & 0.22 & 2.09 & 0.377 & 0.39 & 1.65 & 4.84 & 34.12 & 1.26 & 55 & 89 \\
\hline 42 & 252.48 & 4 & 0.57 & 3.03 & 6.49 & 0.26 & 4.54 & 0.717 & 0.86 & 3.66 & 13.20 & 27.76 & 2.61 & 71 & 46 \\
\hline 43 & 525.30 & 5 & 1.13 & 9.41 & 7.39 & 0.70 & 8.12 & 0.609 & 1.67 & 7.11 & 7.83 & 90.80 & 6.48 & 24 & 2 \\
\hline 44 & 144.27 & 6 & 2.26 & 3.59 & 4.76 & 0.65 & 4.18 & 1.348 & 0.66 & 2.82 & 11.23 & 25.08 & 1.92 & 90 & 69 \\
\hline 45 & 344.09 & 5 & 1.13 & 8.46 & 0.00 & 0.16 & 4.00 & 0.066 & 0.87 & 3.69 & 1.41 & 261.80 & 3.58 & 12 & 30 \\
\hline 46 & 330.39 & 5 & 1.13 & 7.46 & 2.20 & 0.58 & 4.75 & 0.053 & 1.03 & 4.40 & 0.70 & 633.05 & 4.35 & 8 & 16 \\
\hline 47 & 97.39 & 6 & 2.26 & 2.10 & 4.15 & 0.40 & 3.08 & 0.827 & 0.52 & 2.22 & 6.89 & 32.17 & 1.67 & 62 & 77 \\
\hline 48 & 252.48 & 5 & 1.13 & 4.64 & 0.29 & 0.35 & 2.45 & 0.421 & 0.46 & 1.95 & 5.41 & 36.03 & 1.52 & 52 & 79 \\
\hline 49 & 234.45 & 6 & 2.26 & 3.48 & 1.84 & 0.42 & 2.66 & 0.793 & 0.43 & 1.85 & 6.60 & 28.02 & 1.32 & 69 & 86 \\
\hline 50 & 894.50 & 5 & 1.13 & 11.44 & 4.87 & 0.58 & 7.84 & 2.130 & 1.32 & 5.61 & 27.39 & 20.47 & 3.42 & 100 & 32 \\
\hline 51 & 829.58 & 4 & 0.57 & 9.22 & 2.99 & 0.65 & 5.97 & 0.367 & 1.24 & 5.29 & 6.76 & 78.14 & 4.74 & 28 & 11 \\
\hline 52 & 108.21 & 5 & 1.13 & 1.95 & 1.59 & 0.22 & 1.74 & 0.242 & 0.34 & 1.43 & 3.11 & 46.13 & 1.18 & 37 & 90 \\
\hline 53 & 82.96 & 3 & 0.28 & 3.42 & 1.73 & 0.15 & 2.46 & 0.095 & 0.52 & 2.23 & 4.94 & 45.10 & 1.83 & 39 & 74 \\
\hline 54 & 1190.26 & 4 & 0.57 & 14.88 & 1.48 & 0.09 & 7.63 & 0.815 & 1.52 & 6.48 & 27.77 & 23.34 & 4.26 & 94 & 18 \\
\hline 55 & 332.26 & 6 & 2.26 & 5.23 & 6.13 & 0.85 & 5.67 & 1.585 & 0.94 & 4.02 & 15.64 & 25.70 & 2.77 & 82 & 43 \\
\hline
\end{tabular}

Notes: Signif. codes: ${ }^{* * * \prime} 0.01^{\prime * *^{\prime}} 0.05^{\prime * \prime} 0.1^{\prime \prime} 1$

Source: Author's on the basis of provided bank's data 
Table 1b | RAROC and EVA of Surveyed Bank's Clients

\begin{tabular}{|c|c|c|c|c|c|c|c|c|c|c|c|c|c|c|c|}
\hline Client & $\begin{array}{c}\text { Total } \\
\text { Credit } \\
\text { Exposure } \\
\text { in } € \text { ths }\end{array}$ & $\begin{array}{c}\text { PD } \\
\text { rating }\end{array}$ & PD \% & $\begin{array}{l}\text { Interest } \\
\text { Income } \\
\text { in } € \text { ths }\end{array}$ & $\begin{array}{l}\text { Non- } \\
\text { credit } \\
\text { Income } \\
\text { in } € \text { ths }\end{array}$ & $\begin{array}{c}\text { Total } \\
\text { Fee } \\
\text { Income } \\
\text { in } € \text { ths }\end{array}$ & \begin{tabular}{|c|} 
Opera- \\
tional \\
Costs \\
in $€$ ths
\end{tabular} & $\begin{array}{c}\text { Ex- } \\
\text { pected } \\
\text { Loss }\end{array}$ & $\begin{array}{c}\text { Tax in } \\
\epsilon \text { ths }\end{array}$ & $\begin{array}{c}\text { Net } \\
\text { Profit } \\
\text { in } € \text { ths }\end{array}$ & $\begin{array}{l}\text { Risk } \\
\text { Capital } \\
\text { in } € \text { ths }\end{array}$ & $\begin{array}{c}\text { RAROC } \\
\text { in } \%\end{array}$ & $\begin{array}{c}\text { EVA in } \\
\in \text { ths }\end{array}$ & $\begin{array}{l}\text { Clients' } \\
\text { order- } \\
\text { RAROC }\end{array}$ & $\begin{array}{c}\text { Clients } \\
\text { order- } \\
\text { EVA }\end{array}$ \\
\hline 56 & 155.09 & 4 & 0.57 & 2.23 & 3.64 & 0.49 & 2.95 & 0.157 & 0.62 & 2.64 & 2.89 & 91.14 & 2.40 & 23 & 50 \\
\hline 57 & 244.58 & 6 & 2.26 & 4.23 & 2.27 & 0.83 & 3.40 & 0.122 & 0.72 & 3.09 & 1.02 & 302.56 & 3.00 & 11 & 40 \\
\hline 58 & 72.14 & 5 & 1.13 & 1.95 & 1.08 & 0.29 & 1.54 & 0.145 & 0.31 & 1.32 & 3.09 & 42.83 & 1.08 & 42 & 94 \\
\hline 59 & 504.96 & 5 & 1.13 & 7.07 & 2.52 & 0.12 & 4.51 & 0.685 & 0.86 & 3.66 & 14.63 & 25.05 & 2.49 & 91 & 48 \\
\hline 60 & 180.34 & 6 & 2.26 & 3.43 & 5.41 & 0.58 & 4.37 & 0.514 & 0.86 & 3.67 & 4.29 & 85.63 & 3.33 & 27 & 35 \\
\hline 61 & 1082.06 & 3 & 0.28 & 10.82 & 5.77 & 0.22 & 7.80 & 0.299 & 1.66 & 7.06 & 15.62 & 45.17 & 5.81 & 38 & 5 \\
\hline 62 & 360.32 & 5 & 1.13 & 5.84 & 6.13 & 0.17 & 5.63 & 0.838 & 1.08 & 4.59 & 17.88 & 25.68 & 3.16 & 83 & 37 \\
\hline 63 & 721.37 & 4 & 0.57 & 4.69 & 5.05 & 0.76 & 4.87 & 0.737 & 0.93 & 3.96 & 13.61 & 29.13 & 2.87 & 67 & 42 \\
\hline 64 & 360.69 & 3 & 0.28 & 1.80 & 5.77 & 0.18 & 3.60 & 0.432 & 0.71 & 3.02 & 10.78 & 27.99 & 2.15 & 70 & 57 \\
\hline 65 & 608.87 & 5 & 1.13 & \begin{tabular}{|l|}
11.57 \\
\end{tabular} & 1.95 & 0.43 & 6.47 & 0.714 & 1.28 & 5.48 & 15.24 & 35.94 & 4.26 & 53 & 19 \\
\hline 66 & 184.92 & 7 & 4.53 & 4.81 & 3.79 & 0.71 & 4.32 & 1.632 & 0.64 & 2.72 & 8.63 & 31.49 & 2.03 & 64 & 62 \\
\hline 67 & 286.74 & 6 & 2.26 & 9.05 & 2.09 & 0.72 & 5.50 & 0.484 & 1.12 & 4.76 & 4.05 & 117.51 & 4.43 & 19 & 13 \\
\hline 68 & 216.41 & 6 & 2.26 & 4.33 & 2.16 & 0.00 & 3.01 & 0.354 & 0.59 & 2.53 & 2.94 & 86.00 & 2.30 & 26 & 53 \\
\hline 69 & 108.21 & 7 & 4.53 & 1.38 & 0.54 & 0.51 & 1.13 & 0.371 & 0.18 & 0.75 & 1.96 & 38.44 & 0.60 & 48 & 101 \\
\hline 70 & 252.48 & 4 & 0.57 & 4.54 & 3.97 & 0.47 & 4.17 & 0.684 & 0.78 & 3.35 & 12.60 & 26.55 & 2.34 & 75 & 52 \\
\hline 71 & 432.82 & 5 & 1.13 & 7.25 & 7.57 & 0.78 & 7.24 & 0.212 & 1.55 & 6.60 & 2.73 & 241.96 & 6.39 & 13 & 3 \\
\hline 72 & 252.48 & 5 & 1.13 & 2.73 & 9.02 & 0.22 & 5.55 & 1.262 & 0.98 & 4.17 & 16.21 & 25.75 & 2.88 & 80 & 41 \\
\hline 73 & 234.45 & 5 & 1.13 & 2.63 & 1.44 & 0.32 & 2.04 & 0.397 & 0.37 & 1.59 & 5.10 & 31.12 & 1.18 & 65 & 91 \\
\hline 74 & 159.78 & 5 & 1.13 & 3.15 & 4.15 & 0.30 & 3.52 & 0.527 & 0.67 & 2.87 & 11.25 & 25.53 & 1.97 & 84 & 64 \\
\hline 75 & 180.34 & 5 & 1.13 & 2.99 & 1.08 & 0.72 & 2.23 & 0.402 & 0.41 & 1.76 & 5.16 & 34.04 & 1.34 & 56 & 85 \\
\hline 76 & 396.75 & 6 & 2.26 & 10.06 & 2.99 & 0.58 & 6.33 & 1.460 & 1.11 & 4.74 & 12.16 & 38.94 & 3.76 & 47 & 28 \\
\hline 77 & 144.27 & 5 & 1.13 & 1.80 & 1.08 & 0.38 & 1.51 & 0.074 & 0.32 & 1.36 & 0.95 & 142.48 & 1.28 & 17 & 87 \\
\hline 78 & 377.60 & 2 & 0.14 & 4.00 & 3.68 & 0.22 & 3.66 & 0.117 & 0.78 & 3.33 & 7.60 & 43.89 & 2.73 & 41 & 44 \\
\hline 79 & 522.99 & 4 & 0.57 & 6.54 & 3.50 & 0.17 & 4.73 & 0.002 & 1.04 & 4.43 & 0.08 & 5880.35 & 4.42 & 5 & 14 \\
\hline 80 & 454.46 & 4 & 0.57 & 11.07 & 0.00 & 0.69 & 5.46 & 0.641 & 1.08 & 4.59 & 18.28 & 25.09 & 3.13 & 89 & 38 \\
\hline 81 & 180.34 & 4 & 0.57 & 4.33 & 2.89 & 0.34 & 3.51 & 0.461 & 0.68 & 2.91 & 8.50 & 34.22 & 2.23 & 54 & 54 \\
\hline 82 & 200.90 & 6 & 2.26 & 5.02 & 0.54 & 0.28 & 2.71 & 0.337 & 0.53 & 2.27 & 4.22 & 53.68 & 1.93 & 34 & 68 \\
\hline 83 & 134.10 & 6 & 2.26 & 3.85 & 3.72 & 0.41 & 3.70 & 1.139 & 0.60 & 2.54 & 12.23 & 20.79 & 1.56 & 99 & 78 \\
\hline 84 & 412.98 & 7 & 4.53 & \begin{tabular}{|l|}
10.74 \\
\end{tabular} & 0.72 & 1.01 & 5.79 & 0.688 & 1.14 & 4.86 & 3.65 & 133.04 & 4.57 & 18 & 12 \\
\hline 85 & 114.01 & 6 & 2.26 & 1.92 & 4.44 & 0.72 & 3.29 & 0.601 & 0.61 & 2.59 & 5.00 & 51.72 & 2.19 & 35 & 56 \\
\hline 86 & 108.21 & 4 & 0.57 & 1.97 & 0.29 & 0.05 & 1.07 & 0.116 & 0.21 & 0.91 & 3.95 & 23.00 & 0.59 & 95 & 102 \\
\hline 87 & 541.03 & 4 & 0.57 & 5.41 & 0.36 & 0.23 & 2.78 & 0.002 & 0.61 & 2.60 & 0.06 & 4336.72 & 2.60 & 6 & 47 \\
\hline 88 & 188.28 & 7 & 4.53 & 3.24 & 0.54 & 0.50 & 1.98 & 0.497 & 0.34 & 1.45 & 3.62 & 40.19 & 1.16 & 45 & 92 \\
\hline 89 & 252.48 & 5 & 1.13 & 4.54 & 3.35 & 0.66 & 3.97 & 0.875 & 0.71 & 3.01 & 11.24 & 26.76 & 2.11 & 73 & 59 \\
\hline 90 & 144.27 & 6 & 2.26 & 3.23 & 0.00 & 0.42 & 1.69 & 0.086 & 0.36 & 1.51 & 0.72 & 211.26 & 1.46 & 15 & 82 \\
\hline 91 & 216.41 & 5 & 1.13 & 3.35 & 1.44 & 0.17 & 2.30 & 0.409 & 0.43 & 1.82 & 8.73 & 20.88 & 1.12 & 98 & 93 \\
\hline 92 & 90.17 & 5 & 1.13 & 1.49 & 1.98 & 0.36 & 1.78 & 0.263 & 0.34 & 1.45 & 5.61 & 25.84 & 1.00 & 79 & 95 \\
\hline 93 & 90.17 & 6 & 2.26 & 1.72 & 3.07 & 0.50 & 2.46 & 0.894 & 0.37 & 1.57 & 7.45 & 21.14 & 0.98 & 97 & 96 \\
\hline 94 & 405.41 & 4 & 0.57 & 5.05 & 5.81 & 1.30 & 5.64 & 0.689 & 1.11 & 4.72 & 12.69 & 37.18 & 3.70 & 50 & 29 \\
\hline 95 & 126.24 & 2 & 0.14 & 1.83 & 3.61 & 0.00 & 2.52 & 0.068 & 0.54 & 2.31 & 2.16 & 106.58 & 2.13 & 20 & 58 \\
\hline 96 & 252.48 & 6 & 2.26 & 4.80 & 3.97 & 0.22 & 4.17 & 1.343 & 0.66 & 2.81 & 11.19 & 25.12 & 1.92 & 88 & 70 \\
\hline 97 & 649.23 & 5 & 1.13 & 11.87 & 1.80 & 0.88 & 6.75 & 1.331 & 1.23 & 5.24 & 17.12 & 30.59 & 3.87 & 66 & 25 \\
\hline 98 & 57.39 & 5 & 1.13 & 1.04 & 4.33 & 0.69 & 2.81 & 0.220 & 0.57 & 2.45 & 2.83 & 86.68 & 2.22 & 25 & 55 \\
\hline 99 & 252.48 & 5 & 1.13 & 3.79 & 9.74 & 0.72 & 6.61 & 1.524 & 1.16 & 4.95 & 19.57 & 25.29 & 3.39 & 85 & 34 \\
\hline 100 & 252.48 & 6 & 2.26 & 4.80 & 1.95 & 0.25 & 3.25 & 0.765 & 0.57 & 2.42 & 6.38 & 37.93 & 1.91 & 49 & 71 \\
\hline 101 & 342.65 & 6 & 2.26 & 9.08 & 2.52 & 1.19 & 5.94 & 0.006 & 1.30 & 5.55 & 0.05 & 11588.11 & 5.55 & 2 & 7 \\
\hline 102 & 559.06 & 5 & 1.13 & 13.20 & 0.65 & 0.65 & 6.73 & 0.004 & 1.48 & 6.29 & 0.09 & 7315.31 & 6.28 & 4 & 4 \\
\hline
\end{tabular}

Notes: Signif. codes: ${ }^{* * * \prime} 0.01^{\prime * * \prime} 0.05^{\prime * \prime} 0.1^{\prime \prime} 1$

Source: Author's on the basis of provided bank's data 
Alongside the targeted hurdle rate is set to $18 \%$ at the surveyed bank for clients belonging to the medium-sized enterprises segment. This rate represents the required rate of return on the credit exposure provided to these clients, which means the RAROC calculated on the client's level should reach $18 \%$ and more, which is the target in the surveyed bank.

RAROC, nevertheless, does not provide any information on the absolute value of the client's contribution towards the sustainable profit. Such information can be received by using the EVA tool which provides, as stated above, information on the real contribution of a particular client to the generation of economic profit. Furthermore, this is very important on the whole portfolio level. As RAROC is a ratio it can be high even in the case of clients generating small profit, but on a very small amount of risk. On the contrary, in order to maximize EVA, the maximisation of profit is necessary, while considering the cost of risk. In other words, clients with high RAROC cannot always bring high EVA and vice versa as shown below in Table 1. RAROC in Table 1 was calculated in accordance with the Equation 5. The clients were then arranged according to the calculated RAROC (from a client with a highest RAROC to a client with the lowest one). The results of this order are shown in the penultimate column of Table 1. EVA was calculated in accordance with Equation 8, where a hurdle rate of $8 \%$ was used and the clients were then arranged according to the calculated EVA (again from a client with a highest EVA to a client with the lowest one). The results of this order are shown in the last column of Table 1.

\section{Figure 1 | Results of the Survey}

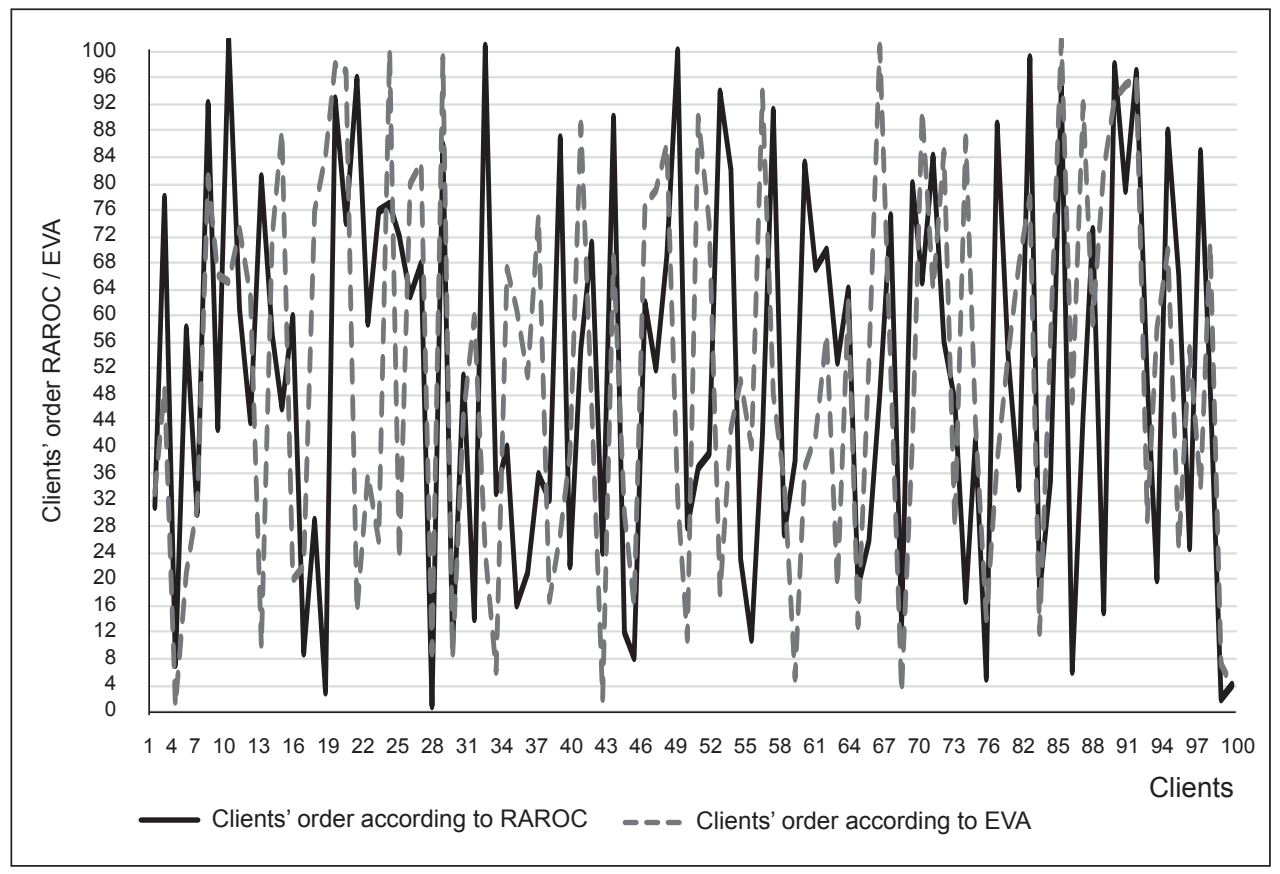

Source: Author's on the basis of the data shown in Table 1. 
As visible, the order of clients according to RAROC usually considerably varies from the order calculated according to EVA. For instance, client No. 27 has the highest RAROC from the whole sample (i.e. $12469.76 \%$ ) and according to the EVA is on the 9 place. Whereas client No. 43 has a much lower RAROC (90.8\%) and is, according to the RAROC order, on the 24 place. Nevertheless, according to the EVA order, it is on the 2 place, which means that it has even higher EVA than client No. 27. The results are also comprehensibly demonstrated in Figure 1, where the continuous line (representing the clients' order according to the calculated RAROC) is not overlapping the dashed line representing the clients' order according to the calculated EVA. If the clients' order which was calculated according to both measures were the same, both lines would fully overlap each other.

\section{Conclusion}

The aim of this paper was to compare ex-ante profitability of a bank's clients from mediumsized enterprises segment calculated according to EVA, with the results calculated according to the RAROC measure.

Initially, the results of previous research in this field with literature review was presented introducing RAROC as currently the most used bank clients' profitability measure. This includes its various modifications based on various alternative arguments for RAROC modification. Regardless of their modification reasons, they all have one thing in common: they are all ratios. Therefore, they always show the bank's managers (and owners) a certain percentage expressing the client's acceptability from the perspective of required rate of return with respect to the client's riskiness. Nevertheless, they do not show the absolute client's contribution to the created value added. In Part 2 the particular variables used in the calculation of RAROC were described, and Part 3 introduced the methodology of EVA tool used in calculation of bank clients' profitability as an alternative to the calculation according to the RAROC measure. Part 4 described the sample of medium-sized enterprises clients in the surveyed banks and the results of the conducted comparison of the calculated profitability according to the RAROC measure and EVA tool. The clients were then arranged from the highest profitability to the lowest one in both cases of used methods (RAROC and EVA). The results showed the clients' order according to their profitability calculated via RAROC measure differed from the profitability calculated via EVA tool. As both RAROC and EVA are fully risk adjusted and based basically on the same variables, it should not matter whether the same amount of EVA is achieved by five credit deals of EUR 100 or one deal of EUR 400. Nevertheless, more (small) deals means more time consumed on them, more workload for relationship managers dealing with the clients and more workload for the credit risk managers dealing with the credit deals approvals. Consequently, if the managers used EVA tool for ex-ante calculation of client's profitability, instead of currently widely spread RAROC, it could provide them with some extra knowledge on the absolute client's profitability and help them manage their portfolio more effectively. This is a necessary condition for success in the growing competition on the bank's market and the necessity to focus on promising clients. 


\section{References}

Crouhy, M., Galai, D., Mark, R. (2001). Risk Management. Comprehensive Sections on Market, Credit and Operational Risk. Mc Graw-Hill, New York. ISBN 0-07-135731-9.

Crouhy, M., Turnbull, S. M., Wakeman, L. M. (1999). Measuring Risk-Adjusted Performance. Journal of Risk, 2(1), 5-35.

Culp, CH. L. (2000). RAROC Revisited. Ex Ante vs. Ex Post RAROC. The Journal of Lending \& Credit Risk Management, 82(6), 50-57.

Damodaran, A. (1999). Value Creation and Enhancement: Back to the Future. Stern School of Business, New York. Available at: http://people.stern.nyu.edu/adamodar/pdfiles/ papers/valcre.pdf

Frykman, D., Tolleryd, J. (2010). Corporate Valuation. Second Edition, Pearson Education Limited. ISBN 978-0-273-72910-5.

Foot, K. A., Stein, J. C. (1998a). Risk Management, Capital Budgeting, and Capital Structure Policy for Financial Institutions: An Integrated Approach. Journal of Financial Economics, 47(1), 55-82, https://doi.org/10.1016/s0304-405x(97)00037-8

Froot, K. A., Stein, J. C. (1998b). A New Approach to Capital Budgeting for Financial Institutions. Journal of Applied Corporate Finance, 11(2), 59-69, https://doi. org/10.1111/j.1745-6622.1998.tb00648.x

Grant, L. J. (1997). Foundations of Economic Value Added. New York: Frank J. Fabozzi. ISBN 1-883249-24-4.

Griffith, J. M. (2004). The True Value of EVA. Journal of Applied Corporate Finance, Fall/Winter, 14(2), 25.

Kraus, C. (2013). EVA/RAROC versus MCEV Earnings: A Unification Approach. The Geneva Papers on Risk and Insurance Issues and Practice, 38(1), 113-136, https://doi.org/10.1057/ gpp. 2012.5

Merton, C., Perold, A. F. (1993). Theory of Risk Capital in Financial Firms. Journal of Applied Corporate Finance, 6(3), 16-32, https://doi.org/10.1111/j.1745-6622.1993.tb00231.x

Milne, A., Onorato, M. (2007). Apples and Pears: The Comparison of Risk Capital and Required Return in Financial Institutions. Available at: http://ssrn.com/abstract=962362

Milne, A., Onorato, M. (2007). The Relationship between Risk Capital and Required Returns in Financial Institutions: Some Preliminary Results. Available at: https://www.researchgate. net

Saita, F. (2007). Value at Risk and Bank Capital Management: Risk Adjusted Performances, Capital Management and Capital Allocation Decision Making. Elsevier Academic Press. ISBN 978-0-12-369466-3.

Schroeck, G. (2002). Risk Management and Value Creation in Financial Institutions. John Wiley \& Sons, Hoboken. ISBN 0-471-25476-2.

Stern, J. M. (2004). Corporate Governance, EVA, and Shareholder Value. Journal of Applied Corporate Finance, 16 (2-3), 91-99, https://doi.org/10.1111/j.1745-6622.2004.tb00541.x

Stern, J. M., Chew, D. H. (2003). The Revolution in Corporate Finance. 4th Ed. Malden: Blackwell. ISBN 1-4051-0781-2.

Stern, J. M., Rolss, I., Shiely, J. S. (2001). The EVA Challenge: Implementing Value-added Change in an Organization. New York: John Wiley \& Sons. ISBN 0-471-40555-8. 
Stern, J. M., Willett, J. T. (2014). A Look Back at the Beginnings of EVA and Value-Based Management. Journal of Applied Corporate Finance, 26(1), 39-46, https://doi.org/10.1111/ jacf.12052

Stewart III, G. B. (1995). EVA Works - but If You Not Make these Common Mistakes. FORTUNE Magazine, 117-118. Available at: http://archive.fortune.com/magazines/fortune/fortune archive/1995/05/01/202480/index.htm.

Stewart III, G. B. (1999). The Quest for Value: A Guide for Senior Managers. New York: Harper Business. ISBN 0-88730-418-4.

Stewart III, G. B. (2013). Best - Practice EVA. The Definite Guide to Measuring and Maximizing Shareholder Value. New Jersey: EVA Dimensions LLC, John Wiley \& Sons. ISBN 9781118639382, https://doi.org/10.1002/9781119204893

Stoughton, N. M., Zechner, J. (2004). Optimal Capital Allocation Using RAROC and EVA. CEPR Discussion Paper No. 4169. Available at: http://www.cepr.org/.

Uyemura, D. G., Kantor, CH. C., Pettit, J. M. (1996). EVA for Banks: Value Creation, Risk Management and Profitability Measurement. Journal of Applied Corporate Finance, 9(2), 94-109, https://doi.org/10.1111/j.1745-6622.1996.tb00118.x

Uyemura, D. G., Van Deventer D. R. (1993). Financial Risk Management in Banking: the Theory and Application of Asset/Liability Management. Bankers Publishing Company. ISBN 1-55738-353-7.

Zaik, E., Walter, J., Kelling, G., James, C. (1996). RAROC at Bank of America: From Theory to Practice. Journal of Applied Corporate Finance, 9(2), 83-93, https://doi. org/10.1111/j.1745-6622.1996.tb00117.x 